\title{
An Intervention to Reduce Hypoglycemia Fear in Parents of Young Kids with Type 1 Diabetes Through Video-Based Telemedicine (REDCHiP): Trial Design, Feasibility, and Acceptability
}

\author{
Arwen M. Marker, MA, ${ }^{1,2}$ Alexandra D. Monzon, MA, MEd, ${ }^{1,2}$ Eve-Lynn Nelson, $\mathrm{PhD}_{1}^{2,3}$ \\ Mark A. Clements, MD, PhD, ${ }^{2,4}$ and Susana R. Patton, PhD, ABPP, CDE ${ }^{2,3, *}$
}

\begin{abstract}
Background: Fear of hypoglycemia (FH) is common in parents of young children with type 1 diabetes (T1D) and problematically linked to maladaptive behaviors to avoid low blood glucose, parenting stress, and burnout. This study examined the feasibility and acceptability of a novel group-based telemedicine intervention to reduce FH in parents of young children with T1D.

Materials and Methods: Forty-three families of a young child with T1D (1-6 years of age; diagnosed with T1D for at least 6 months) enrolled in the study and 36 completed the Reducing Emotional Distress for Childhood Hypoglycemia in Parents (REDCHiP) intervention. We assessed intervention feasibility with rates of attrition, intervention attendance, and fidelity to the treatment manual. We assessed acceptability with treatment satisfaction surveys and qualitative interviews (from a subset of completers; $n=10$ ) about intervention acceptability, facilitators, and challenges.

Results: Study attrition was $21 \%$, including long-term follow-up (16\% before or during the treatment phase). On average, parents attended $94 \%$ of intervention sessions and fidelity to the treatment manual was $89 \%$. Intervention completers reported high satisfaction with the treatment groups (89\% average satisfaction rating). Parent-reported positive influencers of the REDCHiP intervention were increased knowledge, fear awareness, coping strategies, confidence, behavioral parenting strategies, and support, whereas intervention challenges included feeling fearful or overwhelmed, family stress, lack of trust, and difficulty connecting with other group members.

Conclusions: The REDCHiP intervention demonstrated initial feasibility and acceptability. Next steps include determining the intervention's impact on objective parent and child outcomes (e.g., glycemic control, parental FH, and parental stress/distress) as well as large-scale efficacy testing.
\end{abstract}

Keywords: Type 1 diabetes mellitus, Telemedicine, eHealth, Child, Parents, Hypoglycemia, Fear.

\section{Introduction}

$\mathbf{H}$ YPOGLYCEMIA, OR ABNORMALLY low blood glucose (i.e., blood glucose $\leq 70 \mathrm{mg} / \mathrm{dL}$ ), is an acute effect of type 1 diabetes (T1D) that results in unpleasant and potentially dangerous symptoms such as shaking, confusion, lethargy, loss of consciousness, seizures, and even death. ${ }^{1,2}$ Young children younger than age six are at an increased risk for hypoglycemia due to high insulin sensitivity, unpredictable eating and exercise patterns, and difficulty recognizing or communicating symptoms of low blood glucose. 2,3

\footnotetext{
${ }^{1}$ Clinical Child Psychology Program, University of Kansas, Lawrence, Kansas.

${ }^{2}$ Center for Children's Healthy Lifestyles and Nutrition, Children's Mercy Kansas City, Kansas City, Missouri.

${ }^{3}$ Department of Pediatrics, University of Kansas Medical Center, Kansas City, Kansas.

${ }^{4}$ Division of Endocrinology and Diabetes, Department of Pediatrics, Children's Mercy Kansas City, Kansas City, Missouri.

*Center for Healthcare Delivery Science, Nemours Children's Clinic, Jacksonville, Florida.
} 
Consequently, fear of hypoglycemia (FH) is a concern for many parents of young children with T1D, including parents whose child has never experienced severe hypoglycemia. ${ }^{4} \mathrm{FH}$ is an excessive worry/discomfort that interferes with diabetes management through behavioral avoidance and affective distress. ${ }^{5}$ Current estimates suggest that $50 \%-60 \%$ of parents report moderate levels of $\mathrm{FH}$ and $20 \%-30 \%$ of parents report severe $\mathrm{FH}^{6}{ }^{\mathrm{FH}}$ is problematic because parents may engage in maladaptive behaviors to avoid low blood glucose, such as maintaining higher blood glucose levels, leading to poor glycemic control and long-term complications. ${ }^{7,8}$ Consistently high $\mathrm{FH}$ is also linked to parenting stress, distress, and burnout. ${ }^{9-11}$ Thus, there is a critical need for interventions to assist parents of children with T1D to reduce FH.

Although multiple interventions that target adherence and glycemic control exist, a recent systematic review did not identify a single intervention to reduce $\mathrm{FH}$ in parents. ${ }^{6}$ In addition, most psychosocial interventions in pediatric T1D target adolescents. ${ }^{12}$ Thus, we determined a critical need for an ageappropriate intervention to reduce $\mathrm{FH}$ in families of young children, which addresses the unique challenges faced by families of preschoolers and Kindergarteners, such as problematic behaviors (e.g., tantrums and refusal), poor awareness of or inability to verbalize symptoms, and unpredictable eating/exercise behaviors. ${ }^{3,13}$ We aimed to tailor the intervention to parents who are primarily responsible for T1D management at this age.

Our purpose in this study is to present the trial design, feasibility, and acceptability of a new intervention aimed at Reducing Emotional Distress for Childhood Hypoglycemia in Parents (REDCHiP) of young children with T1D. We follow a mixed methods approach, combining quantitative data (e.g., satisfaction ratings, recruitment, and attendance rates) with qualitative interviews to more deeply understand parents' perceptions of the strengths and challenges of the REDCHiP intervention, as well as our telemedicine treatment approach. $^{14}$

\section{Research Design and Methods}

\section{Participants}

We aimed to recruit 40 families of young children with T1D between the ages of 1-6 years. Eligibility criteria included having a young child with a confirmed diagnosis of T1D for greater than 6 months, treatment with intensive insulin therapy through multiple daily injections or continuous subcutaneous insulin infusion, and an English-speaking parent. We did not specify a baseline level of FH for inclusion but anticipated that families experiencing $\mathrm{FH}$ would be more likely to express interest in participating. The local Institutional Review Board approved all study procedures before family enrollment.

\section{Procedures}

We randomly assigned participants to the treatment group or a waitlist control group using block random assignment by child sex. Families randomized to the treatment group began the intervention when we reached a threshold of at least three families per group, whereas families randomized to the waitlist group began the treatment group after a 17-week wait period, on average. We followed those randomized to the treatment group for an additional 15 weeks, on average, after the group ended to measure long-term treatment outcomes.

All participants completed three home visits, which included collection of a child hemoglobin A1c (HbA1c) sample and parent surveys at approximately week 0,14 , and 28 . We also requested that parents upload child glucometer data monthly throughout the study. After completing the intervention, families completed a Treatment Satisfaction Survey and a subset of parents $(n=10)$ completed qualitative interviews for additional feedback about intervention acceptability.

\section{Intervention}

Reducing Emotional Distress for Childhood Hypoglycemia in Parents (REDCHiP) is a manualized intervention based on cognitive behavioral principles to reduce $\mathrm{FH}$ using a three-pronged approach. First, parents work with group leader(s) to increase awareness of FH symptoms, review T1D management skills, and learn goal-setting and problemsolving techniques. Then, parents learn behavioral parenting strategies and personal coping strategies to manage FH (i.e., breathing and relaxation exercises, self-care skills, and finding support). Finally, parents work with group leader(s) to develop a T1D-related fear hierarchy, practice imagined and in vivo exposures to challenge maladaptive thoughts/behaviors and identify/challenge cognitive distortions related to $\mathrm{FH}$.

For example, a parent who refused to let his/her child stay with other caregivers due to FH worked with group leader(s) to challenge catastrophizing thoughts and set goals to gradually include other caregivers in the child's care (e.g., show other caregiver how to treat hypoglycemia, allow other caregiver to treat hypoglycemia with parent supervision, leave child at other caregiver's house for a short period of time, and leave child at other caregiver's house for a few hours). The overall goal of the intervention was to reduce FH and maladaptive avoidance behaviors, as well as promote healthy coping to reduce affective distress.

REDCHiP includes 10 sessions delivered remotely through telemedicine (i.e., real-time secure videoconferencing) using the HIPAA-compliant Zoom application. REDCHiP included seven weekly group sessions and three individual sessions that tailored intervention materials to each family. Sessions were 30-60 min. in duration and typically on weekday evenings (e.g., Monday-Thursday 5:008:00 P.M.). During sessions, parents reviewed homework and had time to ask questions about previous material $(\sim 5-$ $15 \mathrm{~min}$ ), the group leader covered new content and facilitated parent discussion applying new content to personal experiences ( $\sim 30-45 \mathrm{~min})$, and the group leader explained homework for the next week ( $\sim 5 \mathrm{~min})$.

Parents participated through personal computer, smartphone, or tablet, with the option to borrow a study-supplied tablet if they did not own a compatible device. Although we encouraged both parents to participate in the intervention when possible, the parent who self-identified as their child's T1D-specific primary caregiver was enrolled in the study and completed all outcome measures. Group leaders (one to two per group) were clinical psychology doctoral students supervised by a licensed clinical psychologist and certified diabetes educator.

\section{Measures}

Treatment fidelity. We recorded $75 \%$ of intervention sessions $(n=160)$ to assess fidelity to the intervention manual. For 
each session, a member of the research team independently reviewed the content covered out of 12-44 possible content objectives per session. We calculated the percentage of content objectives administered for each session and group, and then averaged these across groups to describe percent fidelity to the treatment manual for each session and in total. We applied a minimum threshold of $80 \%$ fidelity to the manual as a benchmark of treatment fidelity.

Feasibility. A priori, we established benchmarks for session attendance $(\geq 70 \%)$ and participant attrition $(\leq 20 \%)$ to assess feasibility. We counted sessions as attended even in cases where parents rescheduled the session or completed a group session individually (i.e., makeup sessions).

Acceptability. We assessed treatment acceptability using mixed methods. At their post-intervention assessment visit, parents completed a study-specific 15-item Treatment Satisfaction Survey to rate acceptability and satisfaction with the intervention on a 5-point Likert scale from 1 (not at all) to 5 (very or a lot). Responses were converted to a $0-4$ scale for scoring, with sum scores ranging from 0 to 60 . We determined a priori a total score $\geq 48$ as the benchmark for adequate treatment satisfaction (i.e., corresponding to $\geq 80 \%$ satisfaction).

Second, we conducted structured qualitative interviews through telephone with a convenience sample of 10 participants (5 participants who started in the treatment group and 5 who started in the waitlist control group) on a first-come basis for more detailed information about treatment satisfaction. During the phone interview, a researcher used an interview script to ask parents open-ended questions about which aspects of the intervention were most helpful, which aspects of the intervention were not helpful, which intervention skills the family continued to use post-treatment, challenging aspects of the intervention, and participant recommendations to improve the intervention for the future. Researchers included additional follow-up questions, as needed, using the interview script to obtain answers related to all a priori themes.

We audio recorded and transcribed all interviews, and then two researchers (A.M.M. and A.D.M.) independently coded transcripts for thematic codes pertaining to aspects of the intervention that influenced treatment success. We identified codes that fit a priori themes determined before coding using Framework Matrix Analysis theory, which included asking parents highly focused questions to elicit specific information about participant intervention experiences (e.g., positive influencers, stressors, logistics pertaining to the telemedicine format, timing and scheduling, and participant compensation). ${ }^{15}$ We also coded de novo themes discovered based on parent interviews (e.g., additional feedback consistently reported across participants not listed as a priori themes). We present common themes endorsed by at least three participants.

\section{Results}

Forty-three families enrolled and 36 completed the intervention (Fig. 1). On average, parents who completed the intervention were $35.7 \pm 5.1$ years of age, $97.1 \%$ were mothers, and $86.1 \%$ identified as married. The median annual family income was $\$ 80,000-89,000$ and $86.1 \%$ of families reported a socioeconomic status of Hollingshead category 4 or above. Children with T1D were $4.3 \pm 1.5$ years of age, $58.3 \%$ male, 97.2\% Caucasian, $3.0 \%$ Hispanic/Latino, and $2.4 \pm 1.2$ years of age when diagnosed with T1D. Eighty percent of children used insulin pump therapy and $44.4 \%$ also used a continuous glucose monitor. The majority of parents (83.3\%) reported their child experienced a low blood glucose event one to two times per week and one family reported their child had experienced a hypoglycemic seizure. Intervention completers did not differ from noncompleters in reported frequency of hypoglycemia (100\% experienced low blood glucose at least one to two times per week) or hypoglycemic seizures $(p s>0.17)$.

\section{Treatment fidelity}

Average fidelity to the treatment manual across all sessions, groups, and group leaders was $89 \%$. Across 11 intervention cohorts, fidelity ranged from $72 \%$ to $95 \%$ compliance to the treatment manual; and after the first cohort, all other cohorts maintained fidelity of at least $86 \%$. Across the 10 sessions, average fidelity to the treatment manual was $85 \%$ or higher for all sessions, except session 5 (number fear and how to conduct a pattern analysis; average fidelity $=79 \%$ ).

\section{Feasibility}

Out of 43 families who enrolled in the study, 37 began the intervention, 36 completed the intervention, and 34 families completed all study visits, including long-term follow-up (Fig. 1). This resulted in 16\% attrition before or during the treatment phase of the study, and $21 \%$ attrition at any point during the study. For families who began treatment, parents attended $94 \%$ of intervention sessions.

\section{Acceptability}

Out of 36 families who completed the treatment groups, 27 parents completed the Treatment Satisfaction Survey (75\% completion rate). Across all items, parents endorsed a total satisfaction score of $52.3 \pm 5.3$ ) out of 60 points possible, or $88.6 \%$ satisfaction, thus exceeding our benchmark of $80 \%$ intervention satisfaction.

\section{Qualitative interviews}

Positive influencers. Parents identified several themes related to treatment success (see Table 1 for example quotes). The first theme identified was increased knowledge. Parents appreciated learning new T1D-specific information and how group leaders tailored information to young children. Parents cited behavioral parenting strategies (e.g., giving effective commands, using praise, ignoring, and consequences) and T1D-specific coping strategies as important new knowledge. They stated that reviewing T1D-specific skills and practicing as a group helped to increase confidence in their T1D management. Parents also stated that it was beneficial to see discrete data (e.g., pattern analysis and physical activity data from the child's accelerometer) as visual examples of how information applied to their child.

Another theme identified as a positive influencer of intervention success was increased self-awareness of $\mathrm{FH}$ and other T1D-related fears. Parents described positive impacts on both their child's T1D care and their affective 


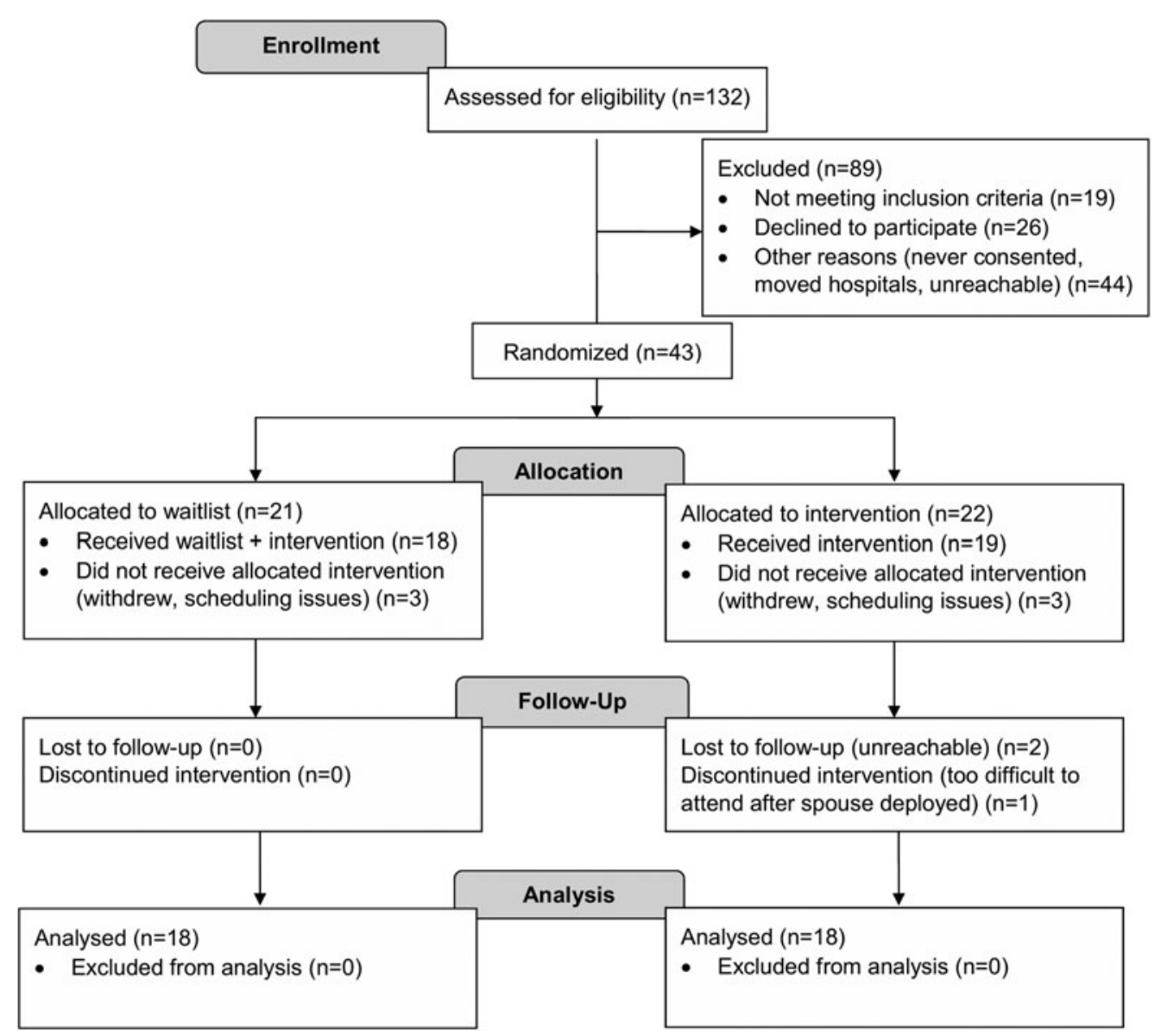

FIG. 1. CONSORT flow diagram of study participants.

state through noticing cognitive distortions and challenging maladaptive behaviors driven by fear (e.g., running blood glucose high and family conflict).

A final theme parents cited as integral to intervention success was the support they received from group leaders and other parents. With this support, parents felt empowered to seek additional help outside the group to cope with the stress of T1D management and felt supported to pursue additional resources (e.g., pumps and continuous glucose monitors).

Stressors. Parents identified continued stressors that made it more difficult to put REDCHiP content into practice in their daily lives (see Table 2 for example quotes). Parents stated that balancing T1D management with parenting multiple children and the unpredictable nature of T1D are challenging and stressful. Parents acknowledged that their mood fluctuates based on their child's blood glucose values, and reported fear and issues with trust as challenging aspects of the REDCHiP intervention (e.g., actions driven by cognitive distortions, not trusting other caregivers to watch their child with T1D, and not trusting devices to give accurate glycemic readings). Some parents noted difficulty because only one parent attended the treatment groups and felt confident to try new skills, while their partner did not; or because parents experienced different fears, complicating the way each parent approached T1D management.

Logistics. Parents provided feedback on logistical aspects of the intervention and trial design, including the tele- medicine format, group dynamics, technology glitches, amount of material covered, and amount of compensation (see Table 3 for example quotes). Parents generally stated that the telemedicine format was acceptable or preferred (e.g., allowed families to participate who otherwise could not), and did not endorse concerns about loss of confidentiality. A few parents reported technology glitches, while learning to use the Zoom application, or issues with the periodic pump uploads.

Parents generally endorsed satisfaction with the number, duration, and spacing of sessions, the amount of information covered in each session, and the treatment format (e.g., seven group sessions and three individual sessions). A few parents noted that it was difficult to feel connected and to interact with other parents through the telemedicine format. Also, a few parents reported some aspects of the intervention were not applicable to their child (e.g., no behavioral problems, not on pump).

Overall, parents stated the monetary compensation was nice, but potentially unnecessary; however, parents appreciated that their child received a toy for allowing study staff to collect an HbA1c blood sample.

\section{Discussion}

Reducing Emotional Distress for Childhood Hypoglycemia in Parents (REDCHiP) is the first intervention developed to reduce $\mathrm{FH}$ in parents of young children with T1D. High treatment fidelity (89\%), low attrition (16\% for intervention 
Table 1. Themes - Facilitators of Intervention Success

\begin{tabular}{|c|c|}
\hline Theme & Quotes \\
\hline $\begin{array}{l}\text { Knowledge/T1D skills } \\
\text { review }\end{array}$ & $\begin{array}{l}\text { "When she was in the hospital, they said, } 70 \text { or below: } 15 \text { grams. } 50 \text { or below: } 30 \text { grams. And } \\
\text { that's all they would say. That's the way we were treating it. No one bothered to tell us 1) the } \\
\text { type of sugars, and 2) because she's so small, she might not need the } 15 \text { grams. [And] after } \\
\text { those } 15 \text { minutes that she does need to have another snack of protein. That was never explained } \\
\text { to us." (mother, 6-year-old girl) } \\
\text { "We always have tried to use [physical] activity as a way to help control or bring down his blood } \\
\text { sugar if he's high. And we can see that working, so... I liked that. I liked seeing it on paper, how } \\
\text { much he was moving." (mother, 3-year-old boy) }\end{array}$ \\
\hline Confidence & $\begin{array}{l}\text { "All the moms in our study were like, we feel like we're failing all the time. But... [the group } \\
\text { leaders] would give a scenario, and we'd be looking at pretend person's numbers [blood glucose } \\
\text { values] and what would we do to change it, and everybody would do the same thing. So then } \\
\text { you kind of go, okay, we all feel like we're failing all the time and yet we all come to the same } \\
\text { conclusion on these scenarios, so we must be doing something right. It's just the diabetes that's } \\
\text { screwed up. Not us." (parent, 1-year-old boy) } \\
\text { "When I took it after the trial, my answers changed a lot. I had a lot more confidence in myself. } \\
\text { When I was done taking the survey, I was like, oh okay. I feel a lot better about this now." } \\
\text { (mother, 4-year-old girl) }\end{array}$ \\
\hline $\begin{array}{l}\text { Behavioral parent } \\
\text { training }\end{array}$ & $\begin{array}{l}\text { "I think when you have a child with diabetes you might tend to go a little bit easier on them. Just } \\
\text { because they're already dealing with so much. So kind of just reinforcing some different ways } \\
\text { to kind of go about disciplining them and making sure that they're still doing what they're } \\
\text { supposed to do, and the extra [diabetes] tasks as well." (mother, 5-year-old girl) } \\
\text { "I think that we learned a lot of strategies to manage his behavior. We are still doing the tokens for } \\
\text { site insertions and shots and things like that. So I think we learned a lot of behaviors to reinforce } \\
\text { with him." (mother, 5-year-old boy) }\end{array}$ \\
\hline Coping strategies & $\begin{array}{l}\text { "Through those coping mechanisms, the initial, we're going to the ER, I just know we're going to } \\
\text { the ER, has calmed down to like, okay, let's try and keep her out of the ER and keep her at } \\
\text { home as long as possible. And this doesn't necessarily have to be an ER trip. Let's try and get } \\
\text { her calmed down and try and fix the solution." (mother, 6-year-old girl) } \\
\text { "The relaxation strategies I've used not so much for care for our child for diabetes but just care for } \\
\text { my child all around. Just having a small child can be challenging without diabetes, so learning } \\
\text { the relaxation techniques and stuff like that for handling the child when tired or disagreeable } \\
\text { was helpful to me as a parent all around." (mother, 4-year-old girl) }\end{array}$ \\
\hline Fear awareness & $\begin{array}{l}\text { "Because of fear of lows, which was the whole point, we carried [child's name] pretty high. And } \\
\text { that's not good on a tiny body either. It helped me to explore some of the reasons why I was } \\
\text { doing that, which is good. My goal was to not carry him so high, and so, as a result of part of } \\
\text { that study and a lot of other reading, we transitioned his diet into a lower carb diet and have } \\
\text { been able to set his goal on his pump lower so that he is maintaining a lower blood sugar." } \\
\text { (mother, 4-year-old girl) } \\
\text { "Blaming each other was an issue before we went through the trial. We used to do that because we } \\
\text { didn't have any other way of dealing with the frustration and the emotion that goes along with } \\
\text { handling it. Because you want somebody to blame. You want some kind of an outlet. And I } \\
\text { went through the trial, and I learned what I learned, it's like, I no longer blame my husband if } \\
\text { her blood sugar's out of range, because you know what? She has diabetes, and we're not a } \\
\text { pancreas. We're only people. For me, the aspects of the trial, the benefits of the trial go far } \\
\text { beyond what each week covered and everything. It was really something that I really needed, } \\
\text { because my life before the trial was different than what it is after." (mother, 4-year-old girl) }\end{array}$ \\
\hline Support & $\begin{array}{l}\text { "Any time you talk to another T1 parent, you're automatically a part of this club that no one wants } \\
\text { to be a part of, but you all understand each other. So it's really nice to talk to other people who } \\
\text { know what you're talking about and understand how much it affects your every moment of } \\
\text { every day." (parent, 1-year-old boy) } \\
\text { "So when I was part of the trial, I was able to voice my emotions that I had relating to diabetes to } \\
\text { someone who understood what I was talking about and would listen to me... They really listened } \\
\text { to me and then gave me helpful feedback, which is like, as a parent, when you're first } \\
\text { diagnosed...it's really challenging and the people around you don't know what you're talking } \\
\text { about. They don't know the stress you're going through." (mother, 4-year-old girl) }\end{array}$ \\
\hline
\end{tabular}

T1, type 1 diabetes; ER, emergency room.

phase of study), high attendance (94\%), and high participantreported satisfaction indicate that the REDCHiP intervention is feasible and acceptable. Using a mixed methods approach, parents reported that reviewing T1D management skills, increasing awareness of $\mathrm{FH}$ and related maladaptive behaviors, learning new coping strategies and behavioral parenting techniques, and seeing data pertinent to their child's T1D were particularly helpful aspects of the intervention. Parents stated that the support the intervention offered and improvements to their self-confidence gained through group 
Table 2. Themes - Continued Stressors

\begin{tabular}{|c|c|}
\hline Theme & Quotes \\
\hline Family stress & $\begin{array}{l}\text { "As a couple, it's easy to say, well, you didn't do that right. It's your fault that her blood sugar is high } \\
\text { because you gave her too much sugar to correct her low. As a couple...you've got regular stressors, } \\
\text { but then you're also trying to deal with the diabetes." (mother, 4-year-old girl) } \\
\text { "Yeah, there are days where I'm trying to work from home. And all three girls are home, and just } \\
\text { trying to stay on top of checking, and dosing, and things like that... So there are some challenges } \\
\text { still." (mother, 5-year-old girl) } \\
\text { "We're military, so there's a lot of aspects for us, in particular in our family, that the military is } \\
\text { involved as far as her diabetes, too. So there is times when I'm a single parent, so dad can't } \\
\text { necessarily check her or dad's not as involved as mom is...Flopping back and forth with dad and } \\
\text { him being home and him being gone affects her blood sugars as well because of the stress." (mother, } \\
\text { 6-year-old girl) }\end{array}$ \\
\hline Fear/overwhelming & $\begin{array}{l}\text { "We both have different fears...He [dad] fears the lows. I fear the highs. And so I'm kind of constantly } \\
\text { keeping her on the lower end, and he's kind of keeping her on the higher end." (mother, 6-year-old } \\
\text { girl) } \\
\text { "When [child name]'s blood sugar would go high or [child name]'s blood sugar would go low, I would } \\
\text { get frustrated because I felt responsible for her blood sugar. It was my job to keep it in range. And } \\
\text { so, if it was out of range, then I would be mad or upset...My emotions were dependent upon her } \\
\text { blood sugar. If she had good blood sugar, then it was okay for me to be happy. If her blood sugar was } \\
\text { out of range, then I was mad at myself or I was sad because I didn't know what to do." (mother, 4- } \\
\text { year-old girl) } \\
\text { "I still have my moments where I let those mind games take over, and I do get on the ride. So I do want } \\
\text { to improve with that. But I'm looking at my fear hierarchy, and I really feel like a lot of this we have } \\
\text { kind of overcome. And so that's kind of exciting to look back on this from even just those few months } \\
\text { ago and realize, we've made progress and this doesn't scare us anymore." (mother, 3-year-old boy) }\end{array}$ \\
\hline Trust & $\begin{array}{l}\text { "Twice my mom has dosed him for calories instead of carbs and caused lows. So trusting her to be } \\
\text { like, you can't dose him for calories. Here's where we're looking. And so, yeah. It's hard for me to } \\
\text { leave. Over meal times, it's especially difficult." (parent, 1-year-old boy) }\end{array}$ \\
\hline $\begin{array}{l}\text { Unpredictability } \\
\text { of T1D }\end{array}$ & $\begin{array}{l}\text { "I think the challenge for me is the inconsistency of diabetes. You can think that things are worked out } \\
\text { and blood sugars look good, not perfect but good, and feel like we're in a good groove here, we're all } \\
\text { getting some sleep. And then something happens, and you can't even put your finger on it. You don't } \\
\text { know what happened, but all of a sudden, blood sugars are really high or we're seeing more lows and } \\
\text { ketones and things just don't seem to be working right. That's what's difficult for me is just it's not } \\
\text { consistent, and so it's hard to keep up with those changes sometimes." (mother, 3-year-old boy) } \\
\text { "Well, that's what we laugh about all the time. As soon as I get a basal set where I'm like, this whole } 24 \\
\text { hours is perfect, it's like a week later, he's growing and it changes again." (parent, 1-year-old boy) }\end{array}$ \\
\hline
\end{tabular}

exercises were integral parts of their perceived intervention satisfaction.

Previous research supports these emergent themes and suggests that learning effective coping strategies, increasing sources of support (e.g., health care team, spouse, friends and family, and support groups), and providing time to develop confidence in T1D management skills can decrease distress in parents of children with T1D. ${ }^{16}$ Our results in this study also suggest that REDCHiP may effectively provide similar levels of support as in-person parent mentoring interventions and support groups associated with increases in confidence, knowledge, access to resources, and more positive outlooks about T1D. ${ }^{17}$

Research suggests that living further away from the diabetes clinic is a risk factor for worse glycemic control and treatment engagement in patients with T1D ${ }^{18}$ (E.L. Nelson, pers. comm.); thus, telemedicine intervention delivery may be one method to eliminate this barrier. In our study, the telemedicine format allowed some families to participate, who would have been otherwise unable to travel to in-person meetings. Moreover, parents reported satisfaction with and a preference for the telemedicine format. While cost analyses of telemedicine in families of young children with T1D are still needed, our data provide preliminary evidence of the benefits of telemedicine as a familiar and acceptable intervention delivery method.

Our findings are in line with existing research among adolescents and school-age youth, which suggest high user satisfaction and positive health outcomes, including improved glycemic control, greater self-monitoring of blood glucose, and greater health care accessibility and communication with providers, using telemedicine. ${ }^{19,20}$ These existing telemedicine interventions largely focused on improving treatment engagement for adolescents with T1D through automated reminders, text support, educational or behavioral interventions delivered through phone or videoconferencing, and the provision of electronic platforms for device uploads and self-monitoring. ${ }^{19,20}$

REDCHiP is novel because it applies these benefits of telemedicine to parents of young children with T1D and their mental health, which is infrequently addressed during the care of youth with chronic disease. The Zoom telemedicine technology also facilitated an efficient assessment of treatment fidelity. Next, it will be important to examine how the REDCHiP intervention impacted objective parent and child outcomes (e.g., child glycemic control, parental FH, and parental stress/distress) to further assess the benefits of this intervention. 
TABle 3. Themes-Logistical Factors

\begin{tabular}{|c|c|}
\hline Theme & Quotes \\
\hline Telemedicine & $\begin{array}{l}\text { "I liked on the computer, because that made it a lot easier. Like, if we had to drive somewhere, } \\
\text { to me, that would have been really hard." (mother, 3-year-old boy) } \\
\text { "I was glad that we were able to do that on the computer. Because I felt like, for me, I would } \\
\text { not have been able to do the trial if it was not on the computer, because... at the time I had a } \\
\text { four-year-old, a three-year-old, and a two-year-old. So I had a lot going on, and I would not, } \\
\text { probably have been able to leave and go meet somebody to do the trial } 10 \text { different times." } \\
\text { (mother, 4-year-old girl) }\end{array}$ \\
\hline $\begin{array}{l}\text { Timing, scheduling, and } \\
\text { materials }\end{array}$ & $\begin{array}{l}\text { "I felt like it was just right. They have sort of breaks built in, which were convenient. } \\
\text { Like...instead of a scheduled group session, it was an individual session the next week. And } \\
\text { they were timed out really well so that it felt like a break... I thought it was very short and } \\
\text { sweet and to the point, which is convenient." (parent, 1-year-old boy) } \\
\text { "I liked the group meetings, and I liked the independent meetings...I think it's good to have } \\
\text { both, because you might not have people say what they want to say in the group setting that } \\
\text { they might say to you individually. So that's a good thing that I would keep." (mother, 6- } \\
\text { year-old girl) }\end{array}$ \\
\hline Group dynamics & $\begin{array}{l}\text { "I think, the group I was in, I felt sometimes it wasn't really interactive. It was kind of a } \\
\text { struggle for some people to talk. I think it would be more impactful if you had a really } \\
\text { interactive group." (mother, 5-year-old boy) } \\
\text { "I didn't feel as connected to the parents. Maybe because we didn't talk as much... Maybe just } \\
\text { having a few minutes each session to kind of talk to the other parents about how they deal } \\
\text { with diabetes. Like, there was a couple times I asked some questions about their kids and at } \\
\text { what point did they start feeling lows at night or if they had family members that had Type } 1 \\
\text { as well. I think it would be nice to kind of maybe have a few minutes to connect that way and } \\
\text { just ask some questions like that." (mother, 3-year-old boy) }\end{array}$ \\
\hline Tech glitches & $\begin{array}{l}\text { "There was one video maybe that didn't work one time or something. But, no, I liked it. I didn't } \\
\text { think that it needed any format changes." (parent, 1-year-old boy) }\end{array}$ \\
\hline Compensation & $\begin{array}{l}\text { "As far as the monetary, honestly, I didn't really pay too much attention to it. I didn't go in it } \\
\text { for the money...And I honestly wasn't expecting toys for [child's name] at all. I think that } \\
\text { was just an added bonus for her... She definitely loved it." (mother, 6-year-old girl) } \\
\text { "I thought [home visits] were really easy. My son loved them because he got a toy, so he was so } \\
\text { excited. I would tell him, they're going to come tomorrow for that study, and we're going to } \\
\text { have to do a finger poke. And he just was so excited to get a toy. And they were always really } \\
\text { short, and the questionnaires weren't difficult to get through. So, yeah, I felt like that was } \\
\text { doable." (mother, 3-year-old boy) }\end{array}$ \\
\hline Not applicable to child & $\begin{array}{l}\text { "I don't have any problems with her eating. I don't really have any behavioral issues with her. } \\
\text { I guess, so no. That wasn't helpful because we just...I think the biggest obstacle for me was } \\
\text { my own mind." (mother, 6-year-old girl) }\end{array}$ \\
\hline
\end{tabular}

Based on the findings presented, the investigators identified some design elements to modify to improve the REDCHiP intervention. Given that most families who dropped out of the intervention either never began treatment or dropped out after completing the treatment phase, increased communication with families during waitlist and follow-up times, or increased compensation during non-intervention periods of the study may improve retention. Young children comprise a minor proportion of the total population of youth with T1D in most diabetes centers; a larger multisite recruitment effort would likely reduce wait times and allow for larger, more diverse cohorts. Importantly, the telemedicine, group videoconferencing format of this trial lends itself to easy dissemination across multiple sites and states. Alterations to the intervention to facilitate rolling admissions (e.g., make session order interchangeable so parents can join at any time) could also reduce wait times for families.

We observed a lower fidelity score for one session across groups, which was largely due to leaders skipping a section on Motivational Interviewing due to needing the full session for families to learn about pattern analysis, which parents cited as a helpful, important aspect of the intervention. Thus, it may be better to move this content to a different session, while still retaining this information, as brief motivational interviewing interventions have shown to effectively promote adherence in children with T1D. ${ }^{21}$

Some parents reported difficulty connecting to other parents in their group as a logistical intervention challenge. Parents also identified family stress, lack of trust (e.g., with devices and other caregivers), feeling overwhelmed, and the unpredictability of T1D as ongoing concerns. Additional exercises specific to these concerns may be important to include in future REDCHiP groups. For example, additional role-playing exercises increase parent confidence to share REDCHiP intervention content with other caregivers (e.g., family members and teachers) involved in the child's T1D management, and the addition of booster sessions may help parents to practice coping strategies and continue exposure exercises in areas that continued to be challenging for them after the end of the intervention. Finally, parent feedback on intervention challenges should inform modifications to the REDCHiP intervention and trial design before conducting a larger, multisite trial. 


\section{Limitations}

This study had some limitations, including a relatively small sample size and limited racial/ethnic diversity across participants. However, demographics of this sample are representative of the larger hospital system in which this study took place. ${ }^{22,23}$ Parents who participated in REDCHiP were mostly mothers, and additional effort to engage fathers in intervention groups is indicated. Although past studies suggest that mothers report higher rates of $\mathrm{FH}$ than fathers, fathers do report $\mathrm{FH}$ and may benefit from treatment. ${ }^{8,10}$ While our qualitative parent interviews yielded both positive and negative feedback, we collected these data from a nonrandom subset of parents using a researcher involved in the intervention. Parent perceptions should be confirmed using interviewers not involved with the intervention and including feedback from parents lost to follow-up to reduce potential sources of response bias.

\section{Strengths}

Importantly, this is the first intervention developed to reduce $\mathrm{FH}$, including behavioral avoidance and affective distress, in parents of young children with T1D. Strengths of this intervention include its grounding in evidence-based therapies (e.g., cognitive behavioral therapy) and its tailored approach for families with young children (e.g., behavioral parenting strategies and review of diabetes management specific to young children). The focus on young children allows families to learn foundational skills that can continue to develop over time, whereas the majority of T1D interventions target adolescents. Another strength of this study is its mixed method approach for examining feasibility and acceptability using both quantitative (e.g., treatment satisfaction survey and attrition) and qualitative outcomes (e.g., participant-reported intervention facilitators and ongoing stressors). Given the early stage of intervention development in this area, this qualitative feedback has the potential to guide future research, as well as improve the REDCHiP intervention.

\section{Conclusions}

Overall, the REDCHiP intervention demonstrated initial feasibility and acceptability. Key aspects of the intervention that helped parents to achieve self-perceived positive outcomes included increasing knowledge of diabetes management skills, behavioral parenting strategies, and coping strategies; increasing awareness of FH; building confidence to handle fear-inducing situations; and opportunities to improve support systems. These will be important treatment components to include in future interventions for parents of youth with chronic illness. Ongoing stressors of high levels of fear, feeling overwhelmed, family stress, lack of trust, and difficulty connecting with other group members should be examined as potential attenuators of treatment outcomes and may need additional intervention.

Next steps include analyzing objective outcomes of the REDCHiP intervention to determine whether the intervention resulted in improvements in parental $\mathrm{FH}$ and stress, related changes in child glycemic control, and a multi-site trial to examine the effectiveness of REDCHiP in a larger, more diverse sample.

\section{Acknowledgment}

The author(s) would like to thank the families who participated in REDCHiP.

\section{Author Disclosure Statement}

M.A.C. is the chief medical officer for Glooko, has consulted with Medtronic Diabetes, Eli Lilly, and receives research support from Abbott Diabetes. No competing financial interests exist for the remaining authors.

\section{Funding Information}

This study was funded by the National Institute of Child Health and Human Development (NICHD) grant R21 HD081502 (to S.R.P). Trial Registration, NCT03879642.

\section{References}

1. Ly TT, Maahs DM, Rewers A, et al.: ISPAD Clinical Practice Consensus Guidelines 2014. Assessment and management of hypoglycemia in children and adolescents with diabetes. Pediatr Diabetes 2014;15(Suppl. 20):180192.

2. Seaquist ER, Anderson J, Childs B, et al.: Hypoglycemia and diabetes: a report of a workgroup of the American Diabetes Association and the Endocrine Society. Diabetes Care 2013;36:1384-1395.

3. Sundberg F, Forsander G: Detection and treatment efficacy of hypoglycemic events in the everyday life of children younger than 7 yr. Pediatr Diabetes 2014;15:34-40.

4. Patton SR, Dolan LM, Henry R, et al.: Fear of hypoglycemia in parents of young children with type 1 diabetes mellitus. J Clin Psychol Med Settings 2008;15:252-259.

5. Cox DJ, Irvine A, Gonder-Frederick L, et al.: Fear of hypoglycemia: quantification, validation, and utilization. Diabetes Care 1987;10:617-621.

6. Barnard K, Thomas S, Royle P, et al.: Fear of hypoglycaemia in parents of young children with type 1 diabetes: a systematic review. BMC Pediatr 2010;10:50.

7. Freckleton E, Sharpe L, Mullan B: The relationship between maternal fear of hypoglycaemia and adherence in children with type-1 diabetes. Int J Behav Med 2014;21: 804-810.

8. Patton SR, Dolan LM, Henry R, et al.: Parental fear of hypoglycemia: young children treated with continuous subcutaneous insulin infusion. Pediatr Diabetes 2007;8: 362-368.

9. Patton SR, Dolan LM, Smith LB, et al.: Pediatric parenting stress and its relation to depressive symptoms and fear of hypoglycemia in parents of young children with type 1 diabetes mellitus. J Clin Psychol Med Settings 2011;18: 345-352.

10. Haugstvedt A, Wentzel-Larsen T, Graue M, et al.: Fear of hypoglycaemia in mothers and fathers of children with type 1 diabetes is associated with poor glycaemic control and parental emotional distress: a population-based study. Diabet Med 2010;27:72-78.

11. Streisand R, Swift E, Wickmark T, et al.: Pediatric parenting stress among parents of children with type 1 diabetes: the role of self-efficacy, responsibility, and fear. J Pediatr Psychol 2005;30:513-521.

12. Winkley K, Ismail K, Landau S, et al.: Psychological interventions to improve glycaemic control in patients with 
type 1 diabetes: systematic review and meta-analysis of randomised controlled trials. BMJ 2006;333:65.

13. Streisand R, Monaghan M: Young children with type 1 diabetes: challenges, research, and future directions. Curr Diab Rep 2014;14:520.

14. Levitt HM, Bamberg M, Creswell JW, et al.: Journal article reporting standards for qualitative primary, qualitative meta-analytic, and mixed methods research in psychology: the APA Publications and Communications Board Task Force Report. Am Psychol 2018;73:26-46.

15. Gale NK, Heath G, Cameron E, et al.: Using the framework method for the analysis of qualitative data in multidisciplinary health research. BMC Med Res Methodol 2013;13:117.

16. Whittemore R, Jaser S, Chao A, et al.: Psychological experience of parents of children with type 1 diabetes: a systematic mixed-studies review. Diabetes Educ 2012;38: 562-579.

17. Sullivan-Bolyai S, Grey M, Deatrick J, et al.: Helping other mothers effectively work at raising young children with type 1 diabetes. Diabetes Educ 2004;30:476-484.

18. Fox DA, Islam M, Amed S: Type 1 diabetes outcomes: does distance to clinic matter? Pediatr Diabetes 2018;19: 1331-1336.

19. Dougherty JP, Lipman TH, Hyams S, et al.: Telemedicine for adolescents with type 1 diabetes. West J Nurs Res 2014; 36:1199-1221.
20. Guljas R, Ahmed A, Chang $\mathrm{K}$, et al.: Impact of telemedicine in managing type 1 diabetes among school-age children and adolescents: an integrative review. J Pediatr Nurs 2014;29:198-204.

21. Erickson SJ, Gerstle M, Feldstein SW: Brief interventions and motivational interviewing with children, adolescents, and their parents in pediatric health care settings: a review. Arch Pediatr Adolesc Med 2005;159:1173-1180.

22. Clements MA, Lind M, Raman S, et al.: Age at diagnosis predicts deterioration in glycaemic control among children and adolescents with type 1 diabetes. BMJ Open Diabetes Res Care 2014;2:e00039.

23. Raman S, Dai H, DeLurgio SA, et al.: High hemoglobin A1c variability is associated with early risk of microalbuminuria in children with T1D. Pediatr Diabetes 2016; 17:398-406.

Address correspondence to: Susana R. Patton, PhD, ABPP, CDE Center Director/Principal Research Scientist, CHDS-FL Nemours Children's Clinic 807 Children's Way Jacksonville, FL 32207

E-mail: susana.patton@nemours.org 